Corrigendum

\title{
Corrigendum to "Protective Effects of Simvastatin, a Lipid Lowering Agent, Against Oxidative Damage in Experimental Diabetic Rats"
}

\author{
Ahmed M. Mohamadin, ${ }^{1,2}$ Ahmed A. Elberry ${ }^{D},{ }^{3}$ Hala S. Abdel Gawad, ${ }^{4}$ Gehan M. Morsy, ${ }^{5}$ \\ and Fahad A. Al-Abbasi ${ }^{6}$ \\ ${ }^{1}$ Department of Chemistry for Health Sciences, Deanery of Academic Services, Health Sciences Track, Taibah University, \\ Al-Madinah, Saudi Arabia \\ ${ }^{2}$ Biochemistry Department, Faculty of Pharmacy, Al-Azhar University, Nasr City, Cairo, Egypt \\ ${ }^{3}$ Department of Clinical Pharmacy, Faculty of Pharmacy, King Abdulaziz University, Jeddah, Saudi Arabia \\ ${ }^{4}$ Department of Physiology, College of Medicine, Taibah University, Al-Madinah, Saudi Arabia \\ ${ }^{5}$ Department of Biochemistry and Nutrition, Women Faculty for Arts, Science and Education, Ain Shams University, Cairo, Egypt \\ ${ }^{6}$ Department of Biochemistry, Faculty of Science, King Abdulaziz University, Jeddah, Saudi Arabia
}

Correspondence should be addressed to Ahmed A. Elberry; berry_ahmed@yahoo.com

Received 5 August 2020; Accepted 5 August 2020; Published 21 December 2020

Copyright ( 2020 Ahmed M. Mohamadin et al. This is an open access article distributed under the Creative Commons Attribution License, which permits unrestricted use, distribution, and reproduction in any medium, provided the original work is properly cited.

In the article titled "Protective Effects of Simvastatin, a Lipid Lowering Agent, Against Oxidative Damage in Experimental Diabetic Rats" [1], author "Gehan M. Morsy" was affiliated to "Biochemistry Department, Applied Science College, Taibah University, Al-Madinah, Saudi Arabia," which is incorrect. The correct affiliation for this author is:

"Department of Biochemistry and Nutrition, Women Faculty for Arts, Science and Education, Ain Shams University, Cairo, Egypt"

\section{References}

[1] A. M. Mohamadin, A. A. Elberry, H. S. Abdel Gawad, G. M. Morsy, and F. A. Al-Abbasi, "Protective effects of simvastatin, a lipid lowering agent, against oxidative damage in experimental diabetic rats," Journal of Lipids, Article ID 167958, 2011. 